\title{
Cuando el feminismo era mala palabra. Algunas experiencias del feminismo porteño
}

\author{
Tarducci, Mónica; Trebisacce, Catalina y Grammático, Karin (2019)
}

Buenos Aires, Espacio Editorial, 158 pp.

\section{Deborah Daich}

Conicet, IIEGE-UBA

Si la lucha por la emancipación de las mujeres es uno de los grandes fenómenos del siglo XX, la actual centuria no parece quedarse atrás. En los últimos años, tanto aquí como en diversas partes del mundo, hemos asistido a una revitalización y masificación del movimiento feminista. En la Argentina, la consigna "Ni una menos"-NUM (y su campaña en las redes que llamó a ocupar las calles) azuzó la movilización de nuevas generaciones y nuevos grupos. Originalmente centrada en la violencia de género y los femicidios, el NUM supo insertarse en un ámbito mayor, el del feminismo y el movimiento amplio de mujeres, e incorporar sus históricas demandas. Así, movilizaciones multitudinarias, y con una visibilidad inusitada, tuvieron lugar durante los últimos cuatro años, especialmente con motivo de los 8 de Marzo -Día Internacional de la Mujer-y la organización del Paro de Mujeres.

Por su parte, el año 2018 nos sorprendió con la posibilidad de discutir el proyecto de la Campaña Nacional por el Derecho al Aborto Legal, Seguro y Gratuito en el Congreso Nacional. Entonces cientos de miles de personas participaron de las concentraciones $y$ vigilias a favor del aborto legal, se multiplicaron los encuentros, charlas y debates al respecto, y las ciudades se tiñeron de verde (el color de la Campaña). Perdimos la votación en el Senado pero no el estado de movilización permanente.

En una coyuntura de recesión económica, devaluación de la moneda e inflación, aumento del desempleo y fuga de capitales, un feminismo revitalizado, inclusivo y popular, se alza con fuerza. Un movimiento dinámico, y cada vez más visible, que reclama por el aborto legal, se pronuncia en contra de la violencia machista y denuncia las políticas neoliberales que nos empobrecen, entre otras tantas demandas.

Protagonistas de esta marea verde y violeta son también las jóvenes y adolescentes. Organizadas desde los centros de estudiantes de sus escuelas, desde grupos formados para la ocasión o sueltas, miles de jóvenes participan de las asambleas, se movilizan y militan orgullosamente este feminismo. A esas jóvenes envalentonadas, que tanta admiración nos provocan y quienes obviamente no han vivido la época en que el feminismo era una mala palabra, se dirige este libro de Mónica Tarducci, Catalina Trebisacce y Karin Grammático. Pero no solo a ellas. Es un libro que se dirige, en verdad, a la sociedad toda y que resulta indispensable para quienes abrazan el feminismo, pues brinda un importante panorama de la lucha de las mujeres porteñas. En otras palabras, es un trabajo riguroso que aporta fragmentos necesarios de la historia del feminismo argentino de la Segunda Ola. ¿Por qué necesarios? Porque recuperar la historicidad de las luchas es clave para enfrentar los nuevos desafíos.

La época que Tarducci, Trebisacce y Grammático reconstruyen es aquella en la que el feminismo era "mala palabra"; tan mala palabra que ni siquiera llegaba a ser "piantavoto" pues lejos estaba aún de ingresar de manera formal o informal en las plataformas de los partidos políticos. Antes bien, era una época de militancias dobles. Era una época en la que el feminismo estaba fuera de las universidades y centros de estudios, por lo que las feministas porteñas estudiaban e intercambiaban los pocos materiales aquí disponibles y aquellos traídos por las compañeras que podían viajar primero, y más tarde por aquellas que volvían del exilio. Era una época en la que no existía internet, en la que el teléfono no era tampoco una tecnología accesible para todo el mundo y en la que, sin embargo, las feministas se las arreglaron para organizarse y tejer, de manera más o menos artesanal, sus diversas acciones.

Que haya habido un tiempo en que el feminismo era mala palabra no quiere decir que ya no existan espacios y foros en los que no lo sea. Dado su carácter emancipatorio, el feminismo sigue siendo un blanco 
privilegiado de los fundamentalismos reaccionarios y de los reaccionarios no tan fundamentalistas. De allí también, la necesidad imperiosa de recuperar nuestra historia de reivindicaciones emancipatorias, de saber de dónde venimos y hacia dónde vamos.

Recuperar y conocer las luchas (y a las luchadoras) que nos precedieron, como afirma Mónica Tarducci en la introducción de este volumen, "no es un ejercicio de mera nostalgia, sino que es la posibilidad de ver las continuidades y descubrir, con asombro, que muchas veces nuestras antecesoras ya reflexionaron y llevaron a la práctica cuestiones que creemos invenciones recientes". Así, no se trata simplemente de un acto de melancolía o de una suerte de elegía del pasado. Con todo, cabe subrayar que si acaso algo hace la nostalgia, en esa añoranza del pasado, es llamar la atención sobre el presente. El nuestro es, sin dudas, un presente convulsionado. Así, si todo pasado se construye desde los intereses del presente, este libro es, antes que nada, una invitación a revisar nuestra memoria feminista de cara a las luchas actuales y del futuro.

Cuando el feminismo era mala palabra consta de tres secciones. La primera, a cargo de Catalina Trebisacce, aborda los años setenta del siglo XX y la irrupción de las primeras organizaciones feministas de la Segunda Ola. Nos acerca, así, a las experiencias de organizaciones autónomas o "feministas puras" como la Unión Feminista Argentina (UFA) y el Movimiento de Liberación Femenina (MLF). Y nos presenta, también, la militancia de las "feministas políticas" con el grupo Muchacha del Partido Socialista de los Trabajadores (PST) y el Movimiento Feminista Popular (MOFEP) del Frente de Izquierda Popular (FIP). Entre unas y otras existieron relaciones diversas, debates y hasta algunas confluencias.

Las "feministas puras" practicaron la concientización, herramienta radical con la que abordar la "raíz de los problemas que subordinan a las mujeres". Estaban abocadas, según lo reseña Trebisacce, a una revolución cultural en el campo de la cultura de masas, a una batalla que venía a disputar los discursos modernos massmediáticos. Se rebelaron contra la construcción de las mujeres como objetos de consumo, la cosificación sexual, los imperativos de belleza y de domesticidad, y contra la maternidad como destino obligado. De aquí, por ejemplo, los volantes repartidos en el día de la madre donde se denunciaba "Madre esclava o reina pero nunca una persona” y, también, acciones como la participación en El mundo de la mujer (1972) de María Luisa Bemberg, una de las fundadoras de UFA. El cortometraje documenta la exposición "Femimundo" y resulta una crítica al mundo de la moda, los mandatos de belleza y el consumo de aparatos domésticos que reproducían y re-creaban roles estereotipados de género. Estas feministas se pronunciaron contra los mandatos heteronormativos y la patologización del clítoris. Reclamaron por el derecho al aborto y la patria potestad indistinta, se pronunciaron contra la derogación del decreto ley que prohibió la difusión y el uso de anticonceptivos, entre otros reclamos. En este punto, sus acciones convergieron con el Frente de Liberación Homosexual (FLH). Así, algunas de las actividades compartidas consistían en irrumpir en las charlas de los sexólogos y desmitificar la temática de la homosexualidad y la sexualidad de las mujeres. Sin embargo, nos advierte la autora, el feminismo de los años setenta no militó en torno al lesbianismo.

En cuanto a las “feministas políticas", estas llevaron adelante una militancia específica sobre la condición de opresión de las mujeres, cuestión que cristalizó en una serie de debates, textos y reivindicaciones. Se relacionaron con las "puras", con quienes compartieron algunas actividades. Trebisacce reconstruye, aquí, el contexto y la situación de los partidos de izquierda de la época, las preocupaciones respecto de un "feminismo cipayo" o de uno burgués reformista que amenazara con diluir la lucha revolucionaria de las clases sociales, y las formas en que estas mujeres pudieron Ilevar adelante su militancia feminista desde la izquierda partidaria. La autora retoma uno de los debates centrales que tanto el FIP como el PST tuvieron que darse, el que estaba relacionado "después de reconocer la condición específica de opresión femenina, con el grado de independencia que aquella militancia tomaría en sus partidos". Tanto en Muchacha como en MOFEP, muchas de sus integrantes terminaron abandonando el espacio debido a cierta insatisfacción respecto del lugar relegado que se le asignaba a la militancia feminista. Con todo, estas militantes pudieron tematizar cuestiones como la participación de las mujeres en la lucha sindical, la doble jornada de trabajo de las mujeres y la conceptualización del feminismo como una lucha anticapitalista, entre otras.

La segunda sección de este libro aborda los años de la última dictadura cívico-militar. Aquí, Karin Grammático aborda el activismo feminista que tuvo lugar durante esta nefasta etapa de nuestra historia. A partir del golpe de Estado de 1976, o incluso un poco antes dado el clima de represión y el terror ya instaurado, las agrupaciones feministas de los años setenta decidieron interrumpir su accionar hasta que se dieran condiciones políticas más favorables. Ahora 
bien, contrariamente a lo que podríamos imaginar, las feministas de entonces no se replegaron completamente. Entonces se desarrolló un feminismo "de catacumbas", retirado de la mirada pública y abocado a las acciones privadas: la continuidad de grupos de concientización o de estudio, ahora disimulados y más pequeños, o la continuación de algunas tareas en completa soledad. Pero también hubo manifestaciones públicas. Algunas acciones tuvieron lugar en la prensa, en la publicación de escritos feministas, en la organización de campañas públicas y jornadas temáticas. Así por ejemplo, Grammático pasa revista a la presencia del feminismo en las páginas de "La Opinión de la Mujer" (suplemento del diario La Opinión) y recupera una solicitada publicada en la revista Así, y reproducida en otros medios, en la que las feministas y mujeres del mundo del espectáculo se pronunciaban a favor de una empleada del Poder Judicial de Mendoza sumariada por estar embarazada siendo soltera.

La última dictadura reforzó el discurso familiarista, ensalzó los valores familiares tradicionales, la maternidad y el cuidado del hogar como misiones "naturales" de las mujeres. A ello se sumaba, por supuesto, la reafirmación de la figura paterna como autoridad máxima del hogar. A pesar de esta narrativa social sostenida desde el terrorismo de estado, las feministas llevaron adelante una Campaña pro Reforma de la Patria Potestad y exigieron el reconocimiento de una patria potestad que pudiera ejercerse de manera indistinta, es decir, de igualdad de derechos y obligaciones para padres y madres. La Campaña, "la acción pública más importante del feminismo porteño en tiempos de dictadura" al decir de Grammático, fue llevada adelante por distintas feministas de los años setenta. Algunas de ellas estaban agrupadas en una organización creada en 1975 y que prosiguió su actividad durante la dictadura: Derechos Iguales para la Mujer Argentina (DIMA).

Durante la dictadura también se formaron la Agrupación de Mujeres Argentinas (AMA), la Unión de Mujeres Socialistas (UMS), el Centro de Estudios de la Mujer (CEM) y la Organización Feminista Argentina (OFA, creada por la ex presidenta del MLF). DIMA, junto con otras militantes, organizó el "Primer Congreso Argentino: La Mujer en el mundo de hoy" en octubre de 1982, al que le seguirían dos encuentros más (recordados por las militantes como "los congresos de DIMA"). Durante este período, se desarrolló también una agenda global de derechos para las mujeres, por lo que Grammático recupera el impacto de los espacios transnacionales en el escenario del feminismo local.
Los años ochenta son abordados por Mónica Tarducci en la tercera y última sección de este libro. Aquí el desafío es enorme, se trata de una década marcada por la Guerra de Malvinas, la transición y luego la apertura democrática, la reivindicación de los derechos humanos y los problemas de la política económica. ¿Cómo compendiar en estas páginas la complejidad de la época y la multiplicidad de acciones y grupos que florecieron en democracia? Como señala Tarducci, "la del ochenta fue una década intensa y novedosa, por llevar a la calle demandas específicamente feministas", una época de una "efervescencia de actividades asombrosa" en la que prima un "discurso de política sexual". La autora resuelve la sección aportando información acerca de las agrupaciones más resonantes que entonces surgieron, recuperando las manifestaciones de los 8 de Marzo y el surgimiento de la Multisectorial y subrayando las campañas y encuentros más importantes.

Pasa revista, así, a la formación, en 1982, de la Asociación de Trabajo y Estudio de la Mujer 25 de Noviembre (ATEM). La fecha con que fue designado el nombre es importante porque refiere al día de lucha contra la violencia social, sexual y política hacia las mujeres, declarado por el I Encuentro Feminista Latinoamericano y del Caribe. Esta agrupación autónoma editó materiales de estudio, brindó espacios de discusión, organizó jornadas y editó la revista Brujas. Partícipe de diversos debates e impulsora del feminismo local, ATEM continúa activa en la actualidad. Tarducci recupera la creación, en 1983, de Lugar de Mujer, nacida como un espacio "de encuentro y reflexión sobre la condición de la mujer" a partir del cual impulsar cambios personales y sociales. Constituida como asociación civil, Lugar de Mujer fue sede de múltiples actividades y publicaba fichas mecanografiadas que servían para difundir el trabajo de autoras feministas. Aborda, también, los grupos Alternativa Feminista y Mujeres en Movimiento así como la creación del Taller Permanente de la Mujer (del que, en los años noventa, surgiría la Librería de Mujeres). Todos estos grupos tenían conexiones con los organismos de Derechos Humanos, adherían a los reclamos de las Madres de Plaza de Mayo y clamaban "por la aparición con vida de los detenidos-desaparecidos, recuperación de los niños secuestrados, repudio a la ley de autoamnistía y castigo a los responsables". Participaban de la Campaña por la libertad de la presa política Hilda Nava de Cuesta, y denunciaban las irregularidades procesales que la condenaron sin pruebas (aquí las resonancias para las feministas que participan o adhieren en la actualidad al Comité por la Libertad de Milagro Sala, son cíclicamente dolorosas). 
Los ochenta son también testigos de algunos hitos importantes en la historia del lesbianismo militante. Tarducci los recupera y subraya los eventos que acompañaron ese desarrollo: los artículos sobre lesbianismo publicados en la revista Alfonsina, el ya clásico artículo de Hilda Rais, el impacto del III Encuentro Feminista Latinoamericano y del Caribe de Bertioga, la conformación de grupos de estudio, el Taller de Existencia Lesbiana, los Cuadernos de Existencia Lesbiana, el Grupo Autogestivo de Lesbianas, entre otros.

Desde el primer 8 de Marzo en democracia, las mujeres salieron a las calles. Resultó un hecho inédito pues nunca antes se había conmemorado esa fecha en la vía pública. La autora recompone el surgimiento de la Multisectorial, integrada por mujeres provenientes de sectores políticos, feministas, gremialistas, independientes y de organismos de derechos humanos. La Multisectorial convocó entonces, y los años subsiguientes, a conmemorar el Día Internacional de la Mujer con un acto público y un documento consensuado.
Finalmente, la sección aborda ampliamente las campañas con las que las feministas buscaron garantizar derechos fundamentales, entre ellos algunos que hasta entonces se creían temas de la esfera privada. Continuaron con la campaña por la patria potestad indistinta, se organizaron en un Movimiento por la Sanción de la Ley de Divorcio Vincular, denunciaron la violencia machista, crearon el Tribunal de Violencia Contra la Mujer Mabel Adriana Montoya, y lucharon por el derecho al aborto legal. Organizaron los Encuentros Nacionales de Mujeres (que este año celebrarán el número 34) y participaron de los encuentros regionales.

Cuando el feminismo era mala palabra resulta un trabajo imprescindible, de lectura amena, con conexiones y continuidades entre secciones; un apunte necesario para seguir tejiendo los hilos de nuestra historia de luchas y reivindicaciones. 